\title{
Market-Neutral Trading with Fuzzy Inference, a New Method for the Pairs Trading Strategy
}

\author{
Mehmet Bayram ${ }^{1}$, Muzaffer Akat ${ }^{2}$ \\ ${ }^{1}$ Marmara University \\ 34722 Kadikoy, Istanbul, Turkey \\ E-mail.mehmetbayram@marun.edu.tr \\ ${ }^{2}$ Ozyegin University \\ Cekmekoy, 34794, Istanbul, Turkey \\ E-mail.muzaffer.akat@ozyegin.edu.tr
}

cross'ref $^{\mathrm{http}: / / \mathrm{dx} \text {.doi.org/10.5755/j01.ee.30.4.14350 }}$

\begin{abstract}
Pricing of financial instruments and stock market predictions is a specific and relatively narrow field, which has been mainly explored by mathematicians, economists and financial engineers. Prediction to make profits in a martingale domain is a hard task. Pairs trading, a market neutral arbitrage strategy, attempts to resolve the drawback of unpredictability and yield market independent returns using relative pricing idea. If two securities have similar characteristics, so should their prices. Deviation from the acceptable similarity range in price is considered an anomaly, and whenever noticed, trading is executed assuming the anomaly will correct itself.

This work proposes a fuzzy inference model for the market-neutral pairs trading strategy. Fuzzy logic lets mimicking human decision-making in a complex trading environment and taking advantage of arbitrage opportunities that the crisp models may miss to acquire for trade decision-making. Spread between two co-integrated stocks and volatility of the spread are used as decision-making inputs. The main focus of this study is the contribution of the fuzzy engine to the existing pairs trading strategies based on the spread measure. Widespread classical 'crisp' techniques are chosen and compared with the developed 'fuzzy' model. Significant enhancement on the performance of the trading strategies has been reported.
\end{abstract}

Keywords: Market-Neutral Trading; Statistical Arbitrage; Pairs Trading; Fuzzy Inference; Decision Making.

\section{Introduction}

Pairs trading is a market neutral trading strategy attempting to resolve the drawback of the unpredictability of particular security using the idea of relative pricing, i.e. quantifying the price of a financial security in terms of the price of another one (Vidyamurthy, 2004). The price of a specific security may be dynamically moving with rapidly changing market circumstances. However, if two securities have similar characteristics, then the prices of both securities should also be similar. For the past twenty years, a vast area of literature has been developed based on this simple trading principle. For the most successful and well-known examples, one can see Faff \& Do Gatev et. al. and Huck (Faff \& Do, 2010; Gatev, Goetzmann, \& Rouwenhorst, 2006; Huck, 2010) among many others. If the prices happen to move away from each other, it could be a sign of mispricing of at least one of the stocks. Noticing the anomaly in this kind of relationship, two stocks are combined to be a pair and the pair of stock is traded with the idea that this anomaly will correct itself. By taking the appropriate position in each stock (a long position in the relatively underpriced stock combined with a short position in the relatively overpriced stock), the trade yields profitability at the time of the correction.

Primary considerations about developing a pairs trading strategy are:

- Identifying appropriate pairs for trading,

- Determining the right time to trade, and
- Determining the time to unwind the opened position. Performances of different pairs trading strategies in terms of these features have been analyzed and compared in a study conducted by Fernholz and Maguire (Fernholz \& Maguire, 2014).

Most common pairs trading methods in practice are based on the deviation from the historical mean distance of price series, using the standard deviation measure, called the spread (Gatev et al., 2006; Vidyamurthy, 2004). Though, the performance of the returns of the pairs trading strategies is quite sensitive to the market conditions (Huck, 2013). Huck studied the market timing and discovered a significant relationship between the performance of a pairs trading strategy and the volatility level of the market (Huck, 2015).

On the other hand, spread and the volatility measures can serve perfectly as inputs for the fuzzy inference models. However, using 'crisp' rules and strategies may lead to missed trading opportunities. This study tries to show how fuzzy inference can be employed to catch those missed opportunities and improve the performance of existing pairs trading strategies.

The primary motivation of this study is to contribute to the decision-making process in a complex and vague domain of stock markets with numerous factors and multiple decision-making actors. Efficiency, uncertainty and very high transaction volume of the stock markets make it hard to seek opportunities to trade for financial gains. On the other hand, it makes it possible to employ complex algorithmic decision- 
making tools to exploit even small deviations from normal circumstances. Therefore, the use of algorithmic trading throughout stock markets in recent years has almost made these strategies one of the main drivers of market values. This study is based on generating an algorithmic pair trading strategy, that employs fuzzy logic as a tool to identify trading opportunities that the 'crisp' algorithmic models may miss to outline. Our primary focus is pairs-formation and trading phases, and in particular, the decision of trade signal generation of the pairs trading strategy. A new fuzzy inference method by an engineering approach is proposed for the trade signal generation step of the process. By introducing fuzzy logic into the algorithm, we try to resolve two of the three main considerations of the technical tools: 'when to open' and 'when to close' the trade.

The organization of the paper is as follows: In the first section, the general background about trading securities, the market efficiency and the pairs trading are laid out. Applications of fuzzy logic and decision-making are reviewed in a broad context. In the next section, the execution of the pairs trading and the integration of the fuzzy logic tools into this trading strategy are explained in detail. A mathematical formulation of the fuzzy engine that is used in the process is also provided. A detailed numerical study comparing pairs trading with and without fuzzy logic is presented in the results section. The improvement of the performance of pairs trading by the addition of the fuzzy decision-making tools has been quantified. We conclude with the results of our work and offer some suggestions for further research in the last section.

\section{Background}

Trading is a fundamental concept of economy that consists of multiple actors participating in negotiation. Today, as money flaw is excessively rapid and high in volume, it can be processed by high technology computer systems of stock markets, under pre-defined strict rules and trusted infrastructure. The general perception and basic strategy for investing in the securities marketplace to obtain valuable returns is to sell the over-valued possessions and buy the under-valued ones. However, since forecasting is very hard and predictability of the future trends is very low in efficient markets, defining a security as over-valued or under-valued is a daunting task.

The model that is most commonly assumed to reflect the movement of the stock price is a log-normal process, that is, the logarithm of the security is assumed to show a process of a random walk (Vidyamurthy, 2004). That means the price is a martingale and expected value in the next time period is equal to the current value. If we use the time series of the historical prices of a particular stock and calculate the returns by differencing this random walk, it yields a white noise series. At this point, we may clearly see that the log-normal assumption of stock prices leads us to the point that the stock returns are essentially white noise processes.

In an efficient market, prices of stocks fully reflect available and relevant information. Economist Fama tested this statement and concluded -with a few exceptions- that the efficient markets model stands well and markets are not exploitable as all the information is embedded in the price of securities (Malkiel \& Fama, 1970). The unpredictability of prices in efficient markets makes investment patterns or arbitrage opportunities inapplicable, as all the actors have the same reach to the relevant information, and they all aim at the same goal of profitability. In theory, a planned security investment approach cannot be successful as a result of the random walk nature of prices.

However, as in the ordinary course of life, anomalies that result in unprecedented and superior profits may occur in the markets. Market efficiency does not require the prices to be always at a fair value. Prices deviate from their expected values, but they should eventually revert following the broadcast of available relevant information. As these deviations occur randomly, an investor's outperformance of the market can only be temporary. The overall performance will always converge to null because of temporary underperformances.

The theory of Efficient Markets (EMT) assuming that prices in the market follow a random walk initiates the process of market price prediction through anticipation of market correction. This paradoxical conclusion was mentioned in a study by Grossman and Stiglitz where acceptance of market efficiency makes the market inefficient for the fact that no one will have incentive exercise arbitrage (Grossman \& Stiglitz, 1980) (Pan, 2011).

\section{Previous Research}

Pricing of the financial instruments and the prediction of the stock markets is a specific and relatively narrow field, which have been mainly explored by the mathematicians, the economists and the financial engineers. As a reason of the unpredictable nature of stock movements, studies in the field of securities trading strategies are quite limited. It is useful to have a broad insight by chronologically reviewing academic research. Pan's review (Pan, 2011) may be considered as a brief historical survey in this context.

Several studies, starting with the dissertation by Louis Bachelier, proposed that prices fluctuate randomly, in no apparent pattern, so that it is impossible to mathematically predict them (Bachelier \& Boness, 1900). Further researchers found no evidence of an ability to outguess the market (Cowles, 1933). The principle of diversification was introduced by an analytical formulation, which proposes preference of holding a large amount of stocks instead of a few would reduce the risk and keep the overall expected return same or given a specific level of tolerance to risk, maximize the expected return (Markowitz, 1952).

The Capital Asset Pricing Model (CAPM) was first introduced in 1964. The theory suggests every investor hold a market portfolio consisting of all existing securities proportional to their capitalization in the market. This is based on the idea of compensating the investor's necessary risk. It is impossible to avoid market risk, therefore market portfolio risk is defined as necessary. Under CAPM, if an investor's portfolio is differing from the market, he is playing a zerosum game. The additional risk taken does not yield additional expected return. Reasoning through this concept leads to buying and holding the market portfolio, namely, passive investing. Combining diversification idea by Markowitz with CAPM by Sharpe produces a new approach that proposes to eliminate the risk which is company-specific, one could hold a group of securities in a portfolio. Thus an investor can 
decide to have a desired risk with respect to the market risk and expect a higher return than he would get if invested in a specific stock.(Sharpe, 1964).

Several studies agree if properly anticipated, changes in price cannot be predicted (Samuelson, 1965). According to a study on US mutual funds, for the scope of the research period, all actively managed mutual funds fail to outperform a broad-based market index on average; and that future performance is not based indications of past performance. This is a study that sets a precedent for market-excess performance by symbol of alpha (Jensen, 1968).

Market efficiency was introduced through defining and distinguishing in three forms: week, semi-strong, and strong. In the weak form of efficiency, the data by historical security prices are reflected in current prices, therefore an investor cannot use the historical price information to predict future. In the semi-strong form of efficiency, publicly available relevant information is reflected by the current price therefore forecasting stock prices using this information would not be possible. In the strong form, all relevant information, public or private, is already embedded in the price, therefore it cannot be employed for further price prediction (Malkiel \& Fama, 1970).

The groundbreaking paper on foundations of CAPM was released on the year 1973, which introduced the basis of pricing for options on CAPM, but concluded by the finding that the price does not depend on the expected return of the underlying security (Black \& Scholes 1973). It was later followed by capital market equilibrium research using incomplete information and concluded with the formation of replication argument based, derived Black Scholes formula (Merton, 1987).

The Arbitrage Pricing Theory (APT) which may be defined as the main alternate to CAPM was proposed in 1976. This theory, by allowing multiple factors which are generic types of economic non-diversifiable risk, extended CAPM. Main idea is that without taking extra risk, one cannot look for excess returns, if contrary was correct, it would be arbitraged by the market actors in a very short amount of time. It supports the argument a portfolio's expected excess return is linked to its exposure to several risk factors and forecasts associated by this factors. As a result, APT constitutes a base for employing several economic factors to forecast asset returns (S. Ross, 1976). In 1992, three factors, which explained $95 \%$ of variability in returns with APT were identified. These are i. market risk, ii. market capitalization, and iii. Book-to market ratio. Later by researchers i.e. Black and Litterman, momentum was added as the fourth factor to this model. The resulting four-factor model is relatively better for the explanation of returns by mutual funds (Fama \& French, 1992). (Pan, 2011).

A related study to our research employing fuzzy operations in this domain is "Stock Data Mining through Fuzzy Genetic Algorithm" proposing a fuzzy genetic algorithm framework for financial pairs mining to discover pair relationships between financial entities such as stocks and markets. The findings show 13 highly correlated pairs, out of total tested 32, came from different sectors. This confirms one conclusion of this study that potential pairs do not necessarily come from the same sector as presumed by traders and financial researchers (Cao, Luo, Ni, Luo, \& Zhang, 2006).

\section{Pairs Trading \& Fuzzy Logic}

The first practice of statistical pairs trading is attributed to Nunzio Tartaglia, a so-called Walstreet quant, who tried to uncover opportunities of arbitrage by a team of physicists, mathematicians, and computer scientists. This gathered group of former academics, by employing sophisticated statistical algorithmic methods and coding trading algorithms executable through automated systems, replaced the intuition and trader's skill out of arbitrage with disciplined, consistent filter rules. Main driver of their algorithms was identification of security pairs, whose prices tended to move in line. It was their great success in 1987, when the group traded these predetermined pairs and reported a $\$ 50$ million profit out of it for their company. Although the Morgan Stanley group disbanded in 1989 after a couple of bad years of performance, pairs trading has since become an increasingly popular market-neutral investment strategy used by individual and institutional traders as well as hedge funds. The increased popularity of quantitative-based statistical arbitrage strategies has also apparently affected profits (Gatev et al., 2006; Vidyamurthy, 2004). It is linked to co-integration (Bossaerts, 1988) and correlation in stock prices, mean reversion (Thaler \& De Bondt, 1985), contrarian strategies (Jegadeesh, Jegadeesh, Titman, \& Titman, 1993) and also to the law of the one price (Huck, 2010).

This strategy involves selling the higher-priced security and buying the lower-priced security with the idea that the mispricing is due to mispricing and will tend to correct itself back to the equilibrium value. The mispricing of securities is determined by the notion of spread. The greatness of the spread means the mispricing magnitude is high which creates a more significant profit potential. Trading by long/short positions from these stock pairs creates profit uncorrelated to market returns, a feature typical of market neutral strategies. Figure 1 demonstrates a simple example of an equilibrium reverting pair and open/closed position zones for the corresponding values.

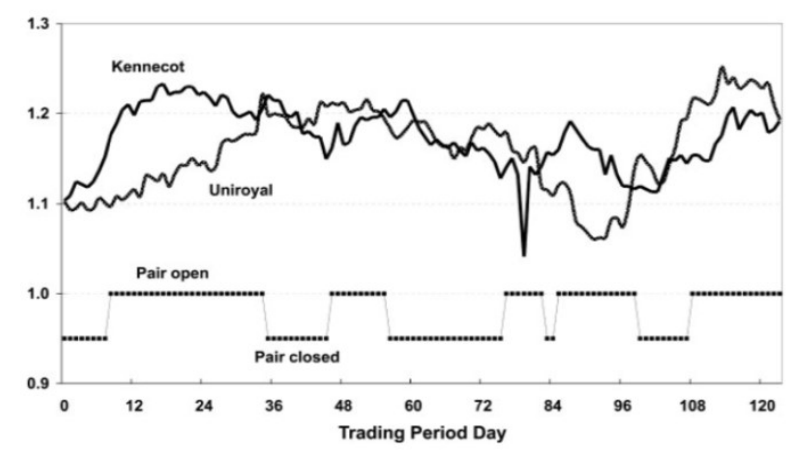

Figure 1. Equilibrium-Reverting Spread in Cointegrated Pairs and Corresponding Trade Position for Spread Values (Gatev et al., 2006). Position for the Normalized Time

Series of the Pair is Opened at the Point of the $2 \sigma$ Historical Standard Deviation of the Spread and Wound up when Pair Intersects at the Historical Mean.

Fuzzy sets (L. A. Zadeh, 1965) providing mathematical foundations to treat imprecision, inexactness, ambiguity, and uncertainty that appear in real problems (Dubois \& Prade, 2015) was introduced by Zadeh, followed by fuzzy logic, an extension of the Boolean logic based on fuzzy sets theory. Linguistic variables (Lotfi A Zadeh, 1973) made it possible 
to mimic human reasoning for decision-making processes. Since its introduction to deal with complex MCDM problems in 1965, fuzzy logic had been employed in part with various classical decision making methods such as ELECTRE (Roy, 1968), Promethee (Brans \& Vincke, 1985), and AHP (Saaty, 1980) which have yielded successful results and made fuzzy logic industrial approved method in various inference systems.

Until the utilization of fuzzy logic for inference systems, most of the techniques employed for the analysis of humanistic, human-centered systems were adaptations of the methods that have been developed over a long period for dealing with mechanistic systems, physical systems governed by the laws of mechanics, electromagnetism and thermodynamics. The effectiveness of computer simulation techniques in the macroscopic analyses of physical systems has brought into vogue the use of computer-based econometric models for purposes of forecasting, economic planning and management (Lotfi A Zadeh, 1973). The distinction between randomness and fuzziness is based on the uncertainty concerning membership or non-membership of an object in a nonfuzzy set in randomness; fuzziness, on the other hand, has to do with classes in which there may be grades of membership intermediate between full membership and nonmembership (Bellman \& Zadeh, 1970). An example graph of a fuzzy membership function for the young-old distinction of individuals for the age values is shown in Figure 2.

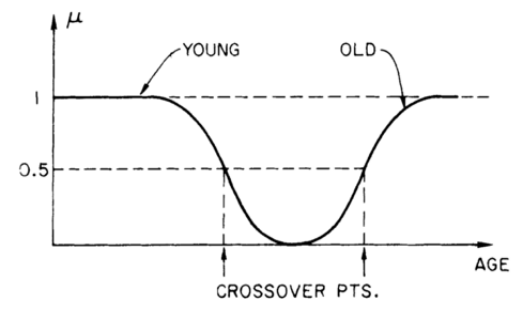

Figure 2. Membership Graph of Linguistic Variables Young and Old for the Corresponding Age Values (Lotfi A Zadeh, 1973)

A fuzzy subset $A$ of a universe of discourse $U$ is characterized by a membership function $\mu_{A}: U \rightarrow[0,1]$ which associates with each element y of $U$ a number $\mu_{A}(y)$ in the interval $[0,1]$ which represents the grade of membership of $y$ in $A$. The support of $\mathrm{A}$ is the set of points in $U$ at which $\mu_{A}(y)$ is positive. A crossover point in $A$ is an element of $U$ whose grade of membership in $A$ is 0.5 . A fuzzy singleton is a fuzzy set whose support is a single point in $U$.

If $A$ is a fuzzy singleton whose support is the point y, we write $A=\mu / y$; where $\mu$ is the grade of membership of $y$ in $A$. To be consistent with this notation, a fuzzy singleton will be denoted by $1 / y$. (Lotfi A Zadeh, 1973).

Stock prices are a subject of frequent fluctuations on the market, and both measurable quantitative (microeconomic, macroeconomic, exchange indicators of foreign countries etc.) and ungrounded qualitative (social, psychological, political and others) factors determine their volatility (Rudzkis \& Valkaviciene, 2014). The approach outlined in Zadeh's paper on the analysis of complex systems and decision processes is based on the premise that the key elements in human thinking are not numbers, but labels of fuzzy sets, that is, classes of objects in which the transition from membership to non-membership is gradual rather than abrupt. Most of the basic tasks by humans do not require a high degree of precision in their execution (Lotfi A Zadeh, 1973). The notion of fuzzy logic to be used in decisionmaking processes takes into account the vagueness of world phenomenon and inaccuracies of human reasoning. Hence, fuzzy systems are very useful in two general contexts: (1) in situations involving highly complex systems whose behaviors are not well understood and (2) in situations where an approximate but fast solution is warranted (T. J. Ross, 2010). Introduction of this approach in the area of finance was based on the same idea of complexity and lack of precision contained in the dynamic nature of stock markets as a result of numerous human actors taking part in the trading activity.

Recent studies based on fuzzy decision-making methods vary in the literature involving different approaches and combined methodologies such as fuzzy multicriteria evaluation of investments using fuzzy TOPSIS (Suder \& Kahraman, 2015). In another study, the vagueness in the finance sector is stated as: "Quite often in finance, future cash amounts and interest rates are estimated. One usually employs educated guesses, based on expected values or other statistical techniques, to obtain future cash flows and interest rates. Statements like approximately between $\$ 12,000$ and $\$ 16,000$ or approximately between $10 \%$ and $15 \%$ must be translated into an exact amount, such as $\$ 14,000$ or $12.5 \%$ respectively. Appropriate fuzzy numbers can be used to capture the vagueness of those statements, and handled the uncertainty of educated guesses for investment analysis by means of fuzzy probability." (Kahraman \& Kaya, 2010).

It is important to note that, in the discourse between humans, a fuzzy statement such as "the stock market has suffered a sharp decline" conveys information despite the imprecision of the meaning (Bellman \& Zadeh, 1970). Several methods have been used to deal with the complex nature of markets including Fibonacci sequence, commonly referred as golden ratio employment for market technical analysis and prediction (Chen, Liu, \& Tong, 2007; Frost \& Prechter, 2005).

Most fuzzy controllers have been designed based on human operator experience and/or control engineer knowledge. It is, however, often the case that an operator cannot tell linguistically what kind of action he takes in a particular situation. In this respect, it is quite useful to give a way to model his control actions using numerical data. Further, if there is no reason to believe that an operator's control is optimal, we have to develop model-based control just as in ordinary control theory. To this aim, it is necessary to consider means for fuzzy modelling of a system (Takagi \& Sugeno, 1985). Main advantages of the Sugeno systems over Mamdani include computational efficiency, linear outputs (making it a better candidate for artificial neural networks), a continuous output surface, well suited for mathematical models.

\section{Methodology}

\section{Explanation of Proposed Model}

In this study, we propose a new model, utilizing the traditional and market approved pairs trading strategy, which we call as 'crisp method' and develop a Sugeno fuzzy decision-making algorithm to exploit the opportunities the 
classical method may miss to acquire. Our concern on reacting before the uninformed technical traders trade had been shared by Gradojevic and Gencay in their study on technical trading (Gradojevic \& Gencay, 2013). We apply the fuzzy algorithm in the trading signal phase, where the decision to open or unwind positions is made. Our methodology consists of two main parts: pairs selection and trade execution.

The spread measure to be used in our study in this context is a perfect linguistic variable, which is commonly used by market arbitrageurs but has been utilized as a crisp mathematical variable in arbitrage strategies throughout the literature. Stock markets, with their inaccurate and hardly predictable nature, fits well in the multicriteria decision making and human reasoning field of research. The complex inputs and human actors taking place makes this domain a candidate for fuzzy inference and artificial neural network systems.

US Nasdaq energy sector stocks that remain in the index for consecutive two years of 2012 and 2013 (67 stocks) were randomly determined as the scope of this study, which yields 2211 possible pairs. Stocks subject to this study are listed in Table 1. We used Yahoo Finance open source URL "http:/ichart.finance.yahoo.com" to download price series autonomously with Matlab during the execution of our algorithm real-time to ensure flexibility for future studies.

Here, the choice of the particular market and the specific sector in this market is purely random. The authors have no motivation in the choice of the market other than the fact that the US Nasdaq market is extremely liquid and therefore efficient. The choice of a specific sector is only for practical purposes. As will be explained below, the number of potential pairs easily gets out of hand once the analyst starts to work with a larger number of stocks. Most importantly, the main contribution of this paper is about how fuzzy logic tools improve the performance of the already existing pairs trading strategies. Since all these strategies are algorithmic, they are indifferent about picking a pair from the same sector or different sectors. One should not conclude that this methodology only applies within a sector. In fact, quite the opposite argument has been well documented in the literature (Cao et al., 2006).

A developed stock market has about 500 stocks yielding about 124.000 pairs (US markets consists of about 5.000 stocks, meaning 12 million pairs) (Vidyamurthy, 2004). Selection is an essential step with vital importance for the success of any pairs-trading algorithm. It involves the procedure of selecting appropriate pairs using a viable relationship testing method for traceability. Running tests for the selection of appropriate pairs in such a set does not seem efficient. Therefore, our first step is to shorten the member list by dividing the stocks to belonged market sectors such as energy, utilities, communication etc. Resulting sub-set may be assumed as potentially 'co-integrated' as belonging to the same market sector makes the members of the set affected by the same type of information flow and market dynamics.

After this simple reduction step, we may proceed to the testing phase of our algorithm, which involves mathematical testing of all possible pairs of our selected sub-set, utilizing co-integration analysis.

The well-known econometricians Engle and Granger observed an interesting phenomenon through their course of examining multivariate series to determine statistically if there is a cause-effect relationship between the variables represented by the time series. According to their study, even if two time series are non-stationary in a discreet manner, it is possible that specific linear combination of the two is stationary in some instance. Which means, the two series move together in somewhat of a lockstep. Engle and Granger coined the term co-integration and proposed the idea in an article. Notably, this was one of the ideas for which they won the Nobel Prize in economics in 2003 (Engle, Granger, \& Mar, 1987; Vidyamurthy, 2004). Cointegration testing will be utilized for the pairs selection step of this study.

In this study, we construct our model for the execution of pairs trading in three basic stages:

- Observation;

- Formation;

- Trading \& Evaluation.

The model is implemented using Matlab software and employing fuzzy logic toolbox in the trade signal decision making step. The flow of the coded modules in the algorithm is represented in Figure 3.

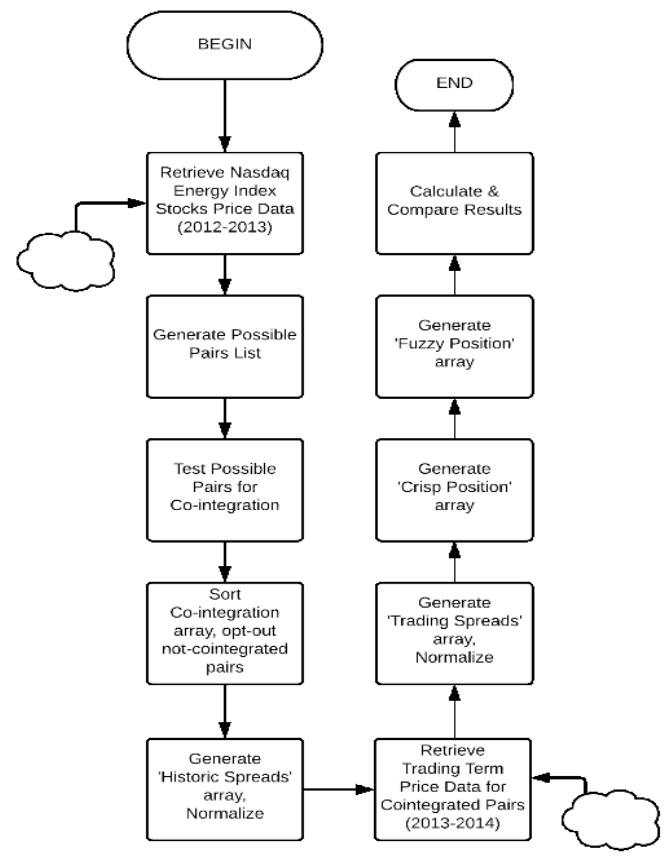

Figure 3. Flow Diagram of the Proposed Trading Algorithm.

The algorithm launches with the observation and assessment of the subject market for the study. We choose an appropriate common market sector, with a high population of volatile stocks and potential returns, which will serve as a set for pairs formation. We generate one trading-year data set for each stock in our subset. In this study, we determined the US Nasdaq energy sector stocks that remain in the index for consecutive two years of 2012 and 2013 (67 stocks), which yields 2211 possible pairs. Stocks subject to this study are listed in Table 1.

Formation: This stage is divided into two phases: training formation and trading formation phase. 
Table 1

67 Nasdaq Energy Sector Stocks Subject to this Study. Stocks Not in the Index for Consecutive two Years is Opted Out

\begin{tabular}{|c|c|c|c|c|}
\hline AXAS & FANG & IEP & PDCE & TGA \\
AHGP & DMLP & ISRL & PLUG & USEG \\
ARLP & EROC & LGCY & PSTR & VNR \\
AETI & EXXI & LLEX & PSIX & VNRAP \\
AMCF & ESCR & LNCO & PNRG & VTNR \\
AREX & ESCRP & LINE & PFIE & WRES \\
BLDP & EVEP & MPET & RCON & WLB \\
BKEP & FES & MARPS & REXX & WPRT \\
BKEPP & FXEN & MMLP & ROSE & WWD \\
BBEP & GLRI & MEMP & ROYL & ZAZA \\
CLMT & GPOR & MGEE & SAEX & ZN \\
CPST & HNRG & MCEP & SEV & \\
CRZO & HERO & ORIG & TESO & \\
CCLP & HOLI & PTEN & TRCH & \\
\hline
\end{tabular}

Training formation: In this phase, we analyze stock prices and construct the necessary time series for pairs formation purposes. We calculate the mean and the variance for each stock's end-of-day price series in our selected sector sub-set of stocks and normalize the extracted one-year dataset using calculated values. After normalization, we choose a matching pair for all stocks with the cointegration testing among all possible pairs of our generated subset of stock prices. Engle\&Granger cointegration method (Engle et al., 1987) employed in this study may be concisely explained as follows:

Consider two time series: $x_{1 t}$ and $x_{2 t}$ which both contain a unit root. If these two series cointegrate, then there exist coefficients $\mu$ and $\beta_{2}$ such that:

$$
x_{1 t}=\mu+\beta_{2} x_{2 t}+u_{t}
$$

Eq. 1 defines an equilibrium. Test for cointegration with E\&G approach consists of testing the series $x_{1 t}$ and $x_{2 t}$ for unit roots then proceed to run the regression equation and saving the residuals. The residual generation step is followed by a test for the presence of unit roots. If the series are cointegrated, residuals should be stationary. Results of the cointegration test employed in this study using Matlab EGCITEST function is summarized as:

Nr. of cointegrated pairs:

The average $\mathrm{p}$-value for cointegrated results: $\quad 0.018$

Nr. of not cointegrated pairs:

The average p-value for not cointegrated results: 0.46

After the co-integration test, we rank and sort the list of pairs from the most co-integrated pair to the least and not cointegrated pairs, followed by opting out and deleting the not cointegrated pairs from our data-set after which we have remained 240 pairs out of 2211 . At the end of training formation phase, we have a final sorted list of co-integrated pairs. List of remaining co-integrated pairs is demonstrated in Table 2 .

Trading formation: In the real world, the trading period of our strategy will work as a real-time system. However, for the sake of statistical analysis and performance testing, we use archived daily price data that had already formed one year after the date range we determined for the 'training formation phase'. We normalize the time series of stock prices for this range using the mean and the variance obtained from the previous phase of training formation.

Table 2

Selected Pairs for Trade Based on the Engle\&Granger Cointegration Measure

\begin{tabular}{|c|c|c|c|c|c|c|c|c|c|c|c|}
\hline AXAS & MGEE & PFIE & SAEX & PSTR & RCON & LINE & RCON & LGCY & WPRT & SEV & WPRT \\
\hline AXAS & MCEP & PFIE & TRCH & LINE & PFIE & MEMP & TRCH & SAEX & WPRT & ORIG & TRCH \\
\hline AXAS & PFIE & PFIE & VNR & EROC & RCON & AXAS & LGCY & ORIG & SAEX & SEV & USEG \\
\hline AXAS & RCON & PFIE & WRES & AXAS & VNR & AHGP & REXX & AXAS & ISRL & AMCF & $\mathrm{ZN}$ \\
\hline AHGP & RCON & PFIE & WWD & AXAS & DMLP & DMLP & PNRG & PNRG & TRCH & MCEP & TRCH \\
\hline ARLP & RCON & RCON & REXX & CPST & PFIE & PSTR & WPRT & MARP & SEV & ESCR & PFIE \\
\hline AETI & RCON & RCON & ROSE & MMLP & REXX & ISRL & ROYL & MPET & WPRT & ESCRP & ROSE \\
\hline BKEP & RCON & RCON & SAEX & AXAS & ARLP & ISRL & VNR & ESCRP & WRES & BKEPP & MEMP \\
\hline BKEPP & MGEE & RCON & TESO & MEMP & SAEX & ISRL & SAEX & BKEPP & DMLP & BKEPP & PNRG \\
\hline BKEPP & PFIE & RCON & TRCH & EROC & PFIE & ISRL & PSTR & ESCRP & MGEE & EROC & WPRT \\
\hline BKEPP & RCON & RCON & VNR & RCON & USEG & HOLI & TESO & PSTR & WRES & PFIE & WLB \\
\hline BKEPP & SAEX & RCON & WRES & TRCH & WWD & CRZO & PFIE & CCLP & WLB & ARLP & WLB \\
\hline BKEPP & TRCH & RCON & WLB & MCEP & PFIE & TESO & WLB & ESCR & ISRL & ISRL & ROSE \\
\hline BBEP & RCON & RCON & WPRT & AETI & REXX & MMLP & PNRG & ISRL & LGCY & AMCF & ZAZA \\
\hline CLMT & RCON & RCON & WWD & BKEP & WLB & ESCR & RCON & BKEP & HERO & AMCF & SEV \\
\hline CCLP & RCON & SAEX & TRCH & PNRG & WLB & AREX & SEV & BKEP & REXX & BKEPP & MCEP \\
\hline DMLP & RCON & SAEX & VNR & ROSE & SAEX & LINE & TRCH & MPET & MCEP & SAEX & WWD \\
\hline ESCRP & PFIE & PFIE & WPRT & FES & RCON & AXAS & PNRG & MCEP & WPRT & ROYL & TGA \\
\hline ESCRP & $\mathrm{RCON}$ & PNRG & REXX & AXAS & ORIG & PSTR & PFIE & SAEX & WRES & ISRL & MEMP \\
\hline ESCRP & SAEX & AMCF & FXEN & AXAS & WRES & VNR & WPRT & HOLI & VTNR & ARLP & MMLP \\
\hline ESCRP & TRCH & LGCY & PFIE & AXAS & MEMP & BKEP & TESO & BKEPP & VNR & AHGP & WLB \\
\hline GLRI & LNCO & HERO & RCON & $\mathrm{TRCH}$ & WPRT & ARLP & PFIE & AXAS & WLB & HOLI & TRCH \\
\hline HOLI & RCON & TRCH & VNR & ESCRP & VNR & ESCRP & ISRL & REXX & WLB & ROYL & TRCH \\
\hline ISRL & LINE & AXAS & BKEPP & HNRG & ROYL & ESCRP & WPRT & CLMT & CCLP & ARLP & DMLP \\
\hline ISRL & PFIE & PDCE & $\mathrm{RCON}$ & ISRL & TRCH & CLMT & WLB & MARP & $\mathrm{ZN}$ & AXAS & CRZO \\
\hline ISRL & WRES & PFIE & ROSE & AXAS & TRCH & AETI & WLB & AETI & PNRG & ISRL & ORIG \\
\hline MPET & RCON & AREX & ISRL & BBEP & SAEX & MEMP & MGEE & ARLP & PNRG & PFIE & ROYL \\
\hline MMLP & $\mathrm{RCON}$ & PNRG & PFIE & AREX & RCON & MEMP & VNR & PSTR & TRCH & HNRG & PFIE \\
\hline MEMP & PFIE & GPOR & $\mathrm{RCON}$ & AXAS & ESCRP & BKEPP & WPRT & ISRL & WPRT & MGEE & PNRG \\
\hline MEMP & RCON & BKEP & CCLP & AHGP & ARLP & AMCF & MARPS & DMLP & TRCH & BKEP & CLMT \\
\hline MGEE & PFIE & RCON & VTNR & EROC & ISRL & EROC & ESCR & VNR & WRES & CCLP & PNRG \\
\hline MGEE & RCON & LGCY & $\mathrm{RCON}$ & IEP & RCON & AXAS & BBEP & AXAS & AHGP & ARLP & REXX \\
\hline MGEE & SAEX & DMLP & PFIE & AHGP & AETI & WRES & WPRT & ESCR & WRES & PFIE & TESO \\
\hline MGEE & TRCH & AXAS & SAEX & $\mathrm{TRCH}$ & WRES & CLMT & TESO & AXAS & MPET & PNRG & SAEX \\
\hline MCEP & RCON & AREX & PFIE & AHGP & MMLP & MPET & PFIE & TRCH & WLB & CRZO & MCEP \\
\hline ORIG & PFIE & CRZO & RCON & EROC & TRCH & BBEP & ISRL & CRZO & PNRG & ROYL & SAEX \\
\hline ORIG & RCON & CPST & RCON & ISRL & RCON & MCEP & PNRG & LINE & ROYL & MPET & TRCH \\
\hline PTEN & $\mathrm{RCON}$ & BBEP & TRCH & DMLP & MCEP & ROSE & TRCH & CLMT & TRCH & FXEN & $\mathrm{ZN}$ \\
\hline PNRG & RCON & BKEPP & ESCRP & RCON & SEV & MPET & PSTR & BBEP & WRES & BKEP & PTEN \\
\hline PFIE & $\mathrm{RCON}$ & BBEP & PFIE & AXAS & WPRT & RCON & ROYL & AHGP & PNRG & AETI & MMLP \\
\hline
\end{tabular}




\section{Trading \& Assessment}

Trading stage of our method is mainly based on the notion of mispricing of pairs, taking a short position in the high valued stock while buying the lower valued stock of the cointegrated pair. We will unwind our position on the next intersection of prices (at the determined minimum spread). The spread of prices in our strategy can be simply denoted as:

$$
\log \left(\mathrm{p}_{\mathrm{t}}^{\mathrm{A}}\right)-\gamma \log \left(\mathrm{p}_{\mathrm{t}}^{\mathrm{B}}\right)=\mu \pm \Delta
$$

where $\mathrm{A}$ and $\mathrm{B}$ are cointegrated and selected stocks with nonstationary time series corresponding them being $\left\{\log \left(\mathrm{p}_{\mathrm{t}}^{\mathrm{A}}\right)\right\}$ and $\left\{\log \left(\mathrm{p}_{\mathrm{t}}^{\mathrm{B}}\right)\right\}$ (Vidyamurthy, 2004); $\mu$, the historical arithmetic mean of spread series and $\Delta$ as the predetermined rule value for taking and unwinding the position.

In this stage, we use the time series data of the trading formation phase that we already generated and normalized. We first execute the trade with the market wide accepted strategy using the crisp rule of $2 \sigma$ historical deviation, also suggested by Gatev et al. (Gatev et al., 2006). Subsequently, we construct a fuzzy decision-making engine to process with similar but fuzzy defined rules and evaluate the gains/losses caused by rules of strict mathematical algorithms vs fuzzy decision making. Figures 3-5 show the fuzzy logic engine structure and triangular input membership functions commonly used in the field of fuzzy decision making. Determined trading rules are demonstrated in Table 3 , and Figure 6 shows the surface view of the inputs and output.

\section{Explanation of Fuzzy Input and Output Variables:}

We considered two fuzzy input variables in this study:

i. First input denotes magnitude of the spread based on deviation from historical mean for the processed pair, with fuzzy linguistic variables: extNet (extremely negative), veryNeg (very negative), neg (negative), closed, pos (positive), veryPos (very positive), extPos (extremely positive) denoted as follows:

$$
\begin{aligned}
& \operatorname{eNeg}(x)=\left\{\begin{array}{c}
0, \text { if } x \leq-5 \\
\frac{x-(-5)}{-3-(-5)}, \text { if } x \in[-5,-3] \\
\frac{-2-x}{-2-(-3)}, \text { if } x \in[-3,-2] \\
0, \text { if } x \geq-2
\end{array}\right. \\
& \operatorname{vNeg}(x)=\left\{\begin{array}{c}
0, \text { if } x \leq-3 \\
\frac{x-(-3)}{-2-(-3)}, \text { if } x \in[-3,-2] \\
\frac{-1-x}{-1-(-2)}, \text { if } x \in[-2,-1] \\
0, \text { if } x \geq-1
\end{array}\right. \\
& \operatorname{Neg}(x)=\left\{\begin{array}{c}
0, \text { if } x \leq-2 \\
\frac{x-(-2)}{-1-(-2)}, \text { if } x \in[-2,-1] \\
\frac{0-x}{0-(-1)}, \text { if } x \in[-1,0]
\end{array}\right. \\
& 0, \text { if } x \geq 0
\end{aligned}
$$

$$
\begin{gathered}
c(x)=\left\{\begin{array}{c}
0, \text { if } x \leq-1 \\
\frac{x-(-1)}{0-(-1)}, \text { if } x \in[-1,0] \\
\frac{1-x}{1-0}, \text { if } x \in[0,1] \\
0, \text { if } x \geq 1
\end{array}\right. \\
\operatorname{Pos}(x)=\left\{\begin{array}{c}
0, \text { if } x \leq 0 \\
\frac{x-0}{1-0}, \text { if } x \in[0,1] \\
\frac{2-x}{2-1}, \text { if } x \in[1,2] \\
0, \text { if } x \geq 2
\end{array}\right. \\
v \operatorname{Pos}(x)=\left\{\begin{array}{c}
0, \text { if } x \leq 1 \\
\frac{x-1}{2-1}, \text { if } x \in[1,2] \\
\frac{3-x}{3-2}, \text { if } x \in[2,3] \\
0, \text { if } x \geq 3
\end{array}\right. \\
\operatorname{extPos}(x)=\left\{\begin{array}{c}
0, \text { if } x \leq 2 \\
\frac{x-2}{3-2}, \text { if } x \in[2,3] \\
\frac{4-x}{4-3}, \text { if } x \in[3,4] \\
0, \text { if } x \geq 4
\end{array}\right.
\end{gathered}
$$

ii. Second input variable of the fuzzy controller denotes the historical volatility measure of the spread for the selected pair as: low, normal and high, denoted as follows:

$$
\begin{gathered}
L(x)=\left\{\begin{array}{c}
0, \quad \text { if } x<0 \\
\frac{x-0}{0-0}, \text { if } x \in[0,0] \\
1, \quad \text { if } x \in[0,1] \\
\frac{2-x}{2-1}, \text { if } x \in[1,2] \\
0, \text { if } x>2
\end{array}\right. \\
N(x)=\left\{\begin{array}{c}
0, \text { if } x \leq 1 \\
\frac{x-1}{2-1}, \text { if } x \in[1,2] \\
\frac{3-x}{3-2}, \text { if } x \in[2,3] \\
0, \text { if } x \geq 3
\end{array}\right. \\
H(x)=\left\{\begin{array}{c}
0, \quad \text { if } x<2 \\
\frac{x-2}{3-2}, \text { if } x \in[2,3] \\
1, \quad \text { if } x \in[3,5] \\
\frac{5-x}{5-5}, \text { if } x \in[5,5] \\
0, \text { if } x>5
\end{array}\right.
\end{gathered}
$$

The output for the proposed inference model is a trading signal to be used for opening, closing positions or keeping the current state. The weighted average method which is one of the more computationally efficient methods (T. J. Ross, 2010) is used to defuzzify the model's fuzzy outputs. The weighted average defuzzification method denoted as follows:

$z^{*}=\frac{\sum \underset{\sim}{\mu_{C}(\bar{z}) \bar{z}}}{\sum \underset{\sim}{\mu_{C}(\bar{z})}}$

Rule base of our strategy is mainly constructed on not generating a trading signal for pairs with moderate historical volatility to avoid the high risk of bankruptcy. When the trading signal is generated, the algorithm takes a short position 
on the higher valued member of the pair while taking a long position on the lower valued one. The investment value is always $\$ 1$ (local currency of the subject market), which can be developed, for different investment patterns and differing risk profiles of selected pair, as implemented in the technical trading application described by Gradojevic and Gencay in their study (Gradojevic \& Gencay, 2013).

Table 3

Rules of the Sugeno Inference Model

\begin{tabular}{|c|c|c|c|c|c|}
\hline \multirow{21}{*}{ 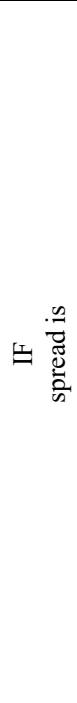 } & \multirow{3}{*}{$\begin{array}{l}\text { extremely } \\
\text { positive }\end{array}$} & \multirow{21}{*}{ 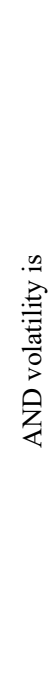 } & high & \multirow{21}{*}{ 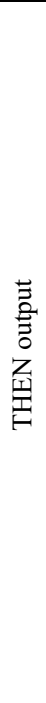 } & no trade \\
\hline & & & normal & & trade positive \\
\hline & & & low & & trade positive \\
\hline & \multirow{3}{*}{$\begin{array}{l}\text { very } \\
\text { positive }\end{array}$} & & high & & no trade \\
\hline & & & normal & & trade positive \\
\hline & & & low & & trade positive \\
\hline & \multirow{3}{*}{ positive } & & high & & trade positive \\
\hline & & & normal & & trade positive \\
\hline & & & low & & trade positive \\
\hline & \multirow{3}{*}{ closed } & & high & & no trade \\
\hline & & & normal & & no trade \\
\hline & & & low & & no trade \\
\hline & \multirow{3}{*}{ negative } & & high & & trade negative \\
\hline & & & normal & & trade negative \\
\hline & & & low & & trade negative \\
\hline & \multirow{3}{*}{$\begin{array}{l}\text { very } \\
\text { negative }\end{array}$} & & high & & no trade \\
\hline & & & normal & & trade negative \\
\hline & & & low & & trade negative \\
\hline & \multirow{3}{*}{$\begin{array}{l}\text { extremely } \\
\text { negative }\end{array}$} & & high & & no trade \\
\hline & & & normal & & trade negative \\
\hline & & & low & & trade negative \\
\hline
\end{tabular}

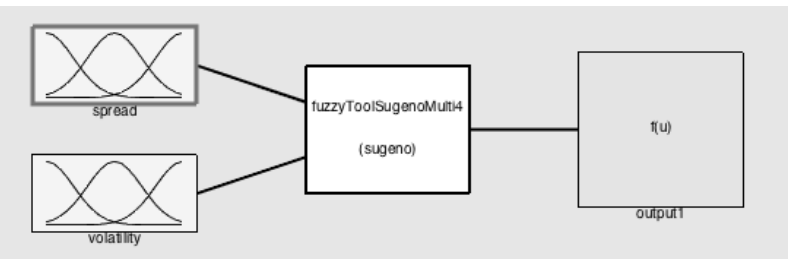

Figure 4. Fuzzy Inference Structure. Sugeno Inference Structure has been Employed as it is More Efficient in Mathematical Models and has the Ability to Work Based on Numerical Time Series Input Without the Need of an Operator

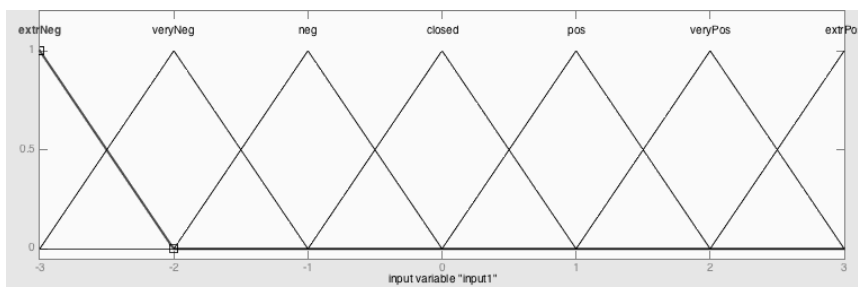

Figure 5. Membership Functions for the Input 'Spread' Based on the Historical Mean of the Difference between Time Series: Extremely Negative, Very Negative, Negative, Closed, Positive, Very Positive, Extremely Positive.

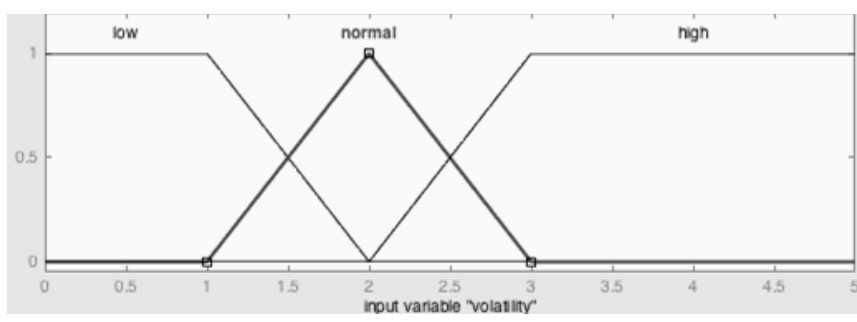

Figure 6. Membership Functions for the Input 'Volatility' Based on the Historical Deviation of the Spread from the Mean: Low, Normal, High.

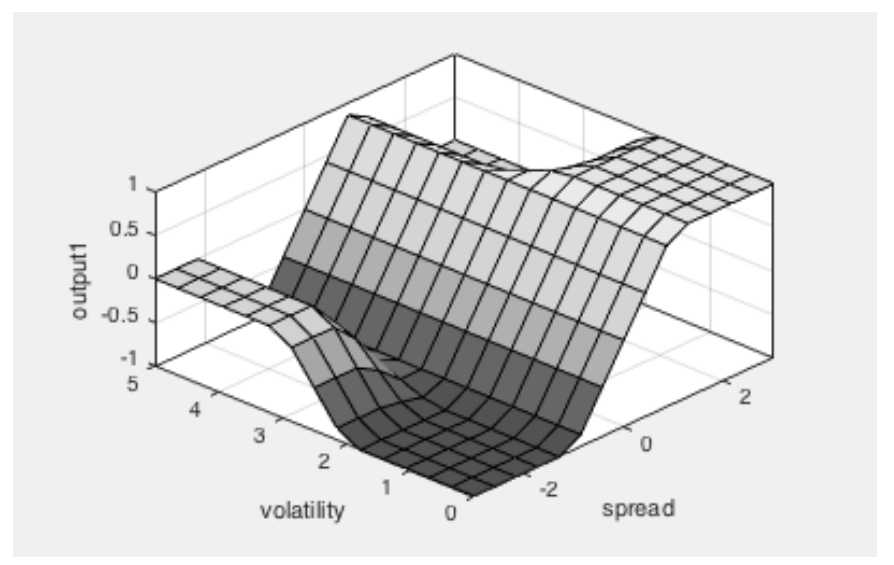

Figure 7. Surface View of the Fuzzy Inference Engine

\section{Results}

We have set up our fuzzy inference algorithm by programming separate functions for each stage using Matlab, utilizing the embedded Fuzzy Logic Designer for trade decision-making. We used Sugeno type fuzzy inference for the fact that Sugeno type fuzzy system better fits controller applications and yields linear outputs. We selected the US Nasdaq Stock Market, energy sector stocks randomly within the date range of 2012-2013 for the training phase and 20132014 for trading phase. We coded the dataset generation function to download and retrieve the open source historical end-of-day price data from the 'Yahoo Finance' URL for flexibility, instead of loading the saved data, as further research may be based on different date range or sectors. For efficiency and small data footprint, we downloaded the necessary pairs' data by determining the unique stocks forming the pairs, instead of all the pairs data for the selected range.

After setting up the classical pairs trading method as 'crisp' trading function and the proposed method as 'fuzzy', we ran our algorithm. Our results function, in which we analyzed returns of our algorithm and running simple comparison, produced the results that the proposed model was 8 percent more profitable than the crisp method for the scope of this study. Our algorithm includes a rule on unwinding the position at the end of the last trading day of the year, no matter the gains or losses, and adds/subtracts the result from the calculation of the overall return.

Figures 8-11 show different results of trade signals by overlapped lines of the crisp and fuzzy method $(1 ;-1$ shows open positions for pairs; 0 shows wound up) for randomly selected pairs, and trading results with the calculation of the return. As demonstrated by the figures, fuzzy logic contains the potential to exploit statistical arbitrage opportunities that the crisp method may miss to acquire as a result of strict nature of the crisp rules, which conflicts the extremely dynamic nature of stock markets. Our proposed algorithm also avoids position openings for relatively low-volatile pairs except for extreme spread condition. 


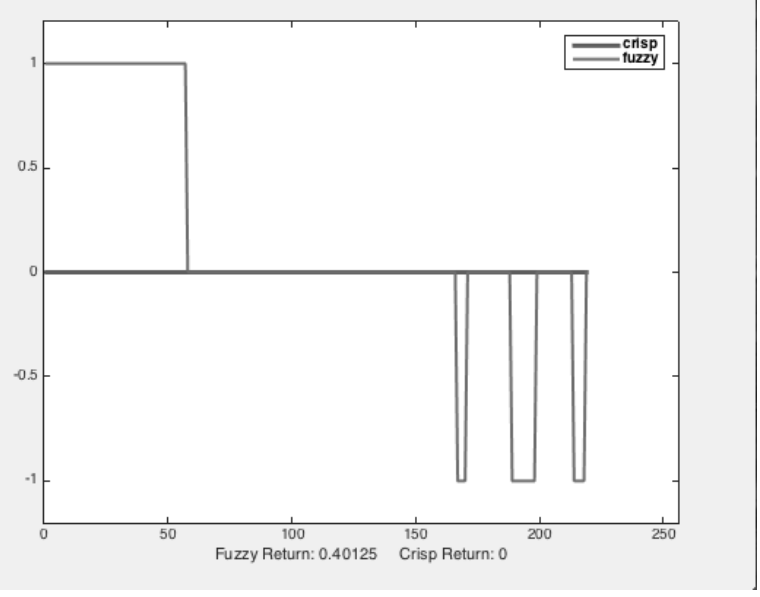

Figure 8. Trading Signal Example, Showing no trade in Classical 'Crisp' Method and four Trade Signals Generated by the Fuzzy Engine.

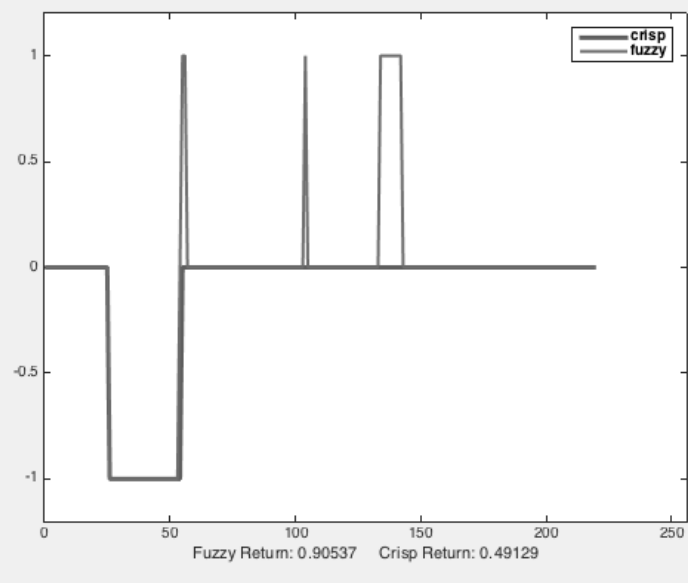

Figure 9. Fuzzy vs Crisp Engines Seen Opening and Unwinding Positions at the Exact Same Time However Fuzzy Engine Opens \& Unwinds Positions three Times More.

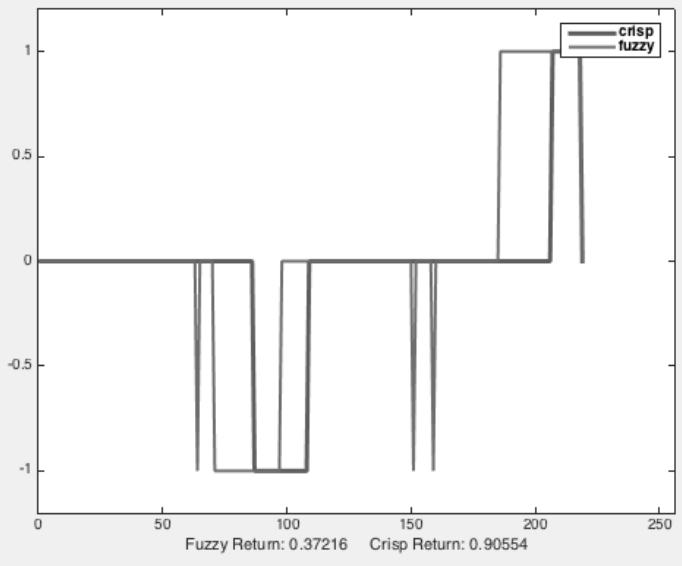

Figure 10. The Fuzzy Method is Not Universally Profitable, as it May fail to Defeat the Crisp Method in Minor Cases Where Further Optimisation may be Considered.

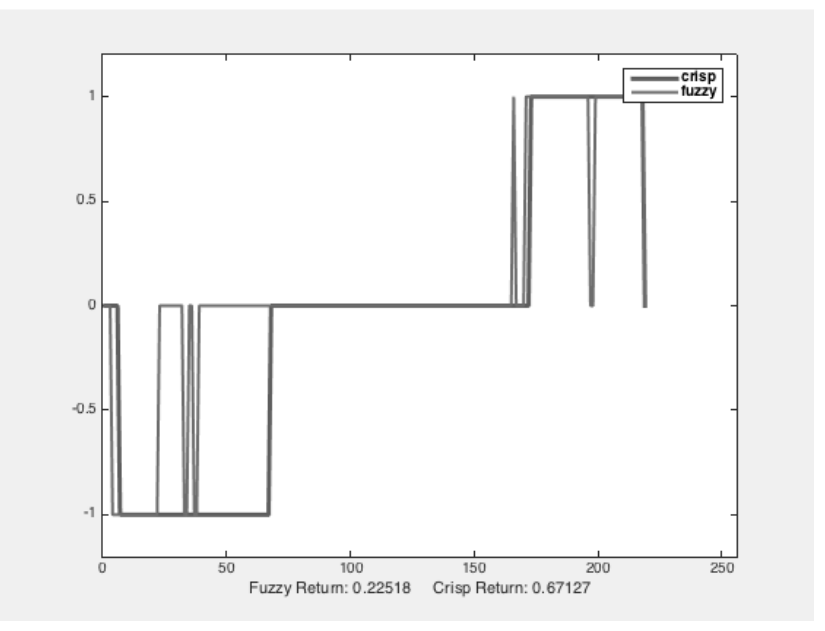

Figure 11. The Fuzzy Engine May Open and Unwind Positions Several Times While the Crisp Strategy Keeps Position Open Which May end in More Profit in the Crisp Side.

\section{Conclusions}

In this study we proposed a new statistical arbitrage method for the pairs trading, a market neutral trading strategy for low risk in the unpredictable market, employing Sugeno type fuzzy inference in the trade decision making step of the strategy for higher efficiency and profitability. Analyzing the results of our implementation and comparing with the commonly accepted classical pairs trading method results, first employed by Nunzio Tartaglia and his colleagues and tested by Gatev et al. between 1962-2002 (Gatev et al., 2006), we conclude for this study that our method is more profitable for the randomly determined sector in US Nasdaq Stock Market and within a randomly selected date range.

The training (observation) period and trading time range which was static (1 year) in this study, can be implemented as a moving process for further studies that could hold greater efficiency. This study neglected transaction costs and generated unwinding signal in the last trading day of the year. Capital to invest and/or portfolio determination can also be considered as fuzzy input and outputs for further studies.

Although fuzzy logic had been used in different studies of finance and investment related papers such as Gradojevic and Gencay's technical trading based study (Gradojevic \& Gencay, 2013), this work is the first study on the application of fuzzy decision-making system in trade decision making for distance based pairs trading strategy. Therefore, we used generally accepted fuzzy rule base with triangular membership functions, which may be developed using complex and various market inputs in further studies. We believe that the main contribution of this work as we desired had been the implementation of fuzzy decision making in pairs trading area as an introduction.

Research should be carried out using various market and investor-related inputs in different markets, considering differing fixed and variable costs, possible co-integrated pairs from different indexes and sectors. One can also fuzzify some other technical indicators in the algorithm. The stock selection step of the pairs trading strategy can also be tried to improve by fuzzifying the selection criteria. As this study yielded improvement in profitability, we believe that fuzzy logic with the capability of mimicking human decision-making processes and modelling complex systems holds excellent potential in finance applications, and should be employed in further studies on algorithmic trading systems. 


\section{References}

Bachelier, L., \& Boness. (1900). Theorie de la speculation. Annales Scientifiques de l'Ecole Normale Superieure. University of Paris, Sorbonne. https://doi.org/10.24033/asens.476

Bellman, R. E., \& Zadeh, L. A. (1970). Decision-making in a fuzzy environment. Management Science. https://doi.org/10.12 87/mnsc.17.4.B141

Bossaerts, P. (1988). Common nonstationary components of asset prices. Journal of Economic Dynamics and Control, 12 , 347-364. https://doi.org/10.1016/0165-1889(88)90045-0

Brans, J., \& Vincke, P. (1985). A preference ranking organization method: the PROMETHEE method for MCDM. Management Science, 31(6), 647-656. https://doi.org/10.1287/mnsc.31.6.647

Cao, L., Luo, C., Ni, J., Luo, D., \& Zhang, C. (2006). Stock Data Mining through Fuzzy Genetic Algorithm. In Proceedings of the 2006 Joint Conference on Information Sciences (JCIS 2006). Kaohsiung, Taiwan: DBLP. https://doi.org/10.29 91/jcis.2006.129

Chen, B. C. B., Liu, X. L. X., \& Tong, S. T. S. (2007). Adaptive neural control of uncertain MIMO nonlinear systems. IEEE Transactions on Fuzzy Systems, 15(3), 674-692. https://doi.org/10.1109/TFUZZ.2006.880008

Cowles, A. (1933). Can stock market forecasters forecast? Econometrica, 1(July), 301-324. https://doi.org/10.23 07/1907042

Dubois, D., \& Prade, H. (2015). The legacy of 50 years of fuzzy sets: A discussion. Fuzzy Sets and Systems, 281, $21-31$. https://doi.org/10.1016/j.fss.2015.09.004

Engle, R. F., Granger, C. W. J., \& Mar, N. (1987). Co-Integration and Error Correction : Representation , Estimation , and Testing, 55(2), 251-276. https://doi.org/10.2307/1913236

Faff, R., \& Do, B. (2010). Does Simple Pairs Trading Still Work? Financial Analysts Journal, 66(4), 83-95. https://doi.org/10.2469/faj.v66.n4.1

Fama, E. F., \& French, K. R. (1992). The cross-section of expected stock returns. Journal of Finance, 47(June), 427-465. https://doi.org/10.1111/j.1540-6261.1992.tb04398.x

Fernholz, R., \& Maguire, C. (2014). The Statistics of Statistical Arbitrage Logarithmic Return of Portfolios, 63(5), 46-52. https://doi.org/10.2469/faj.v63.n5.4839

Frost, A. J., \& Prechter, R. (2005). Elliott Wave Principle: Key To Market Behavior (10th ed.). New Classics Library.

Gatev, E., Goetzmann, W. N., \& Rouwenhorst, K. G. (2006). Pairs trading: Performance of a relative-value arbitrage rule. Review of Financial Studies, 19(3), 797-827. https://doi.org/10.1093/rfs/hhj020

Gradojevic, N., \& Gencay, R. (2013). Fuzzy logic, trading uncertainty and technical trading. Journal of Banking and Finance, 37(2), 578-586. https://doi.org/10.1016/j.jbankfin.2012.09.012

Grossman, S. S. J., \& Stiglitz, J. (1980). On the impossibility of informationally efficient markets. The American Economic Review, 70(3), 393-408. https://doi.org/10.1177/0003065108330523

Huck, N. (2010). Pairs trading and outranking: The multi-step-ahead forecasting case. European Journal of Operational Research, 207(3), 1702-1716. https://doi.org/10.1016/j.ejor.2010.06.043

Huck, N. (2013). The high sensitivity of pairs trading returns. Applied Economics Letters, 20(14), 1301-1304. https://doi.org/10.1080/13504851.2013.802121

Huck, N. (2015). Pairs trading: does volatility timing matter? Applied Economics, 47(57), 6239-6256. https://doi.org/10. $1080 / 00036846.2015 .1068923$

Jegadeesh, N., Jegadeesh, N., Titman, S., \& Titman, S. (1993). Returns to Buying Winners and Selling Losers: Implications for Stock Market Efficiency. The Journal of Finance, 48(1), 65. https://doi.org/10.2307/2328882

Jensen, M. C. (1968). The performance of mutual funds in the period of 1945-1964. Journal of Finance, 23(May), 389-416. https://doi.org/10.2307/2325404

Kahraman, C., \& Kaya, I. (2010). Investment analyses using fuzzy probability concept. Technological and Economic Development of Economy, 16(1), 43-57. https://doi.org/10.3846/tede.2010.03

Malkiel, B., \& Fama, E. (1970). Efficient capital markets: A review of theory and empirical work*. The Journal of Finance, 25(2), 28-30. https://doi.org/10.1111/j.1540-6261.1970.tb00518.x

Markowitz, H. (1952). Portfolio selection. Journal of Finance, 7(March), 77-91. https://doi.org/10.1111/j.1540-6261.1952. tb01525.x 
Merton, R. C. (1987). A simple model of capital market equilibrium with incomplete information. Journal of Finance, 42(July), 483-510. https://doi.org/10.1111/j.1540-6261.1987.tb04565.x

Pan, H. (2011). a Basic Theory of Intelligent Finance. New Mathematics and Natural Computation, 07(02), $197-227$. https://doi.org/10.1142/S1793005711001895

Ross, S. (1976). The arbitrage theory of capital asset pricing. Journal of Economic Theory, 13(December), 341-360. https://doi.org/10.1016/0022-0531(76)90046-6

Ross, T. J. (2010). Fuzzy Logic with Engineering Applications: Third Edition. Fuzzy Logic with Engineering Applications: Third Edition. https://doi.org/10.1002/9781119994374

Roy, B. (1968). Classement et choix en presence de points de vue multiples. RAIRO - Operations Research - Recherche Operationnelle, 2(V1), 57-75. Retrieved from http://eudml.org/doc/104443 https://doi.org/10.1051/ro/196802V100571

Rudzkis, R., \& Valkaviciene, R. (2014). Econometric models of the impact of macroeconomic processes on the stock market in the Baltic countries. Technological and Economic Development of Economy, 20(4), 783-800. https://doi.org/10.3846/ 20294913.2014.949901

Saaty, T. L. (1980). The Analytic Hierarchy Process. Decision Analysis. New York: McGraw-Hill. https://doi.org/10.2 1236/ADA214804

Samuelson, P. (1965). Proof that properly anticipated prices fluctuate randomly. Industrial Management Review, 6, 41-49.

Sharpe, W. F. (1964). Capital asset prices: A theory of market equilibrium under conditions of risk. Journal of Finance, 19(September), 425-442. https://doi.org/10.1111/j.1540-6261.1964.tb02865.x

Suder, A., \& Kahraman, C. (2015). Multicriteria analysis of technological innovation investments using fuzzy sets. Technological and Economic Development of Economy, 4913(November), 1-19. https://doi.org/10.3846/20294913. 2014.994191

Takagi, T., \& Sugeno, M. (1985). Fuzzy identification of systems and its applications to modeling and control. Systems, Man and Cybernetics, IEEE Transactions On, SMC-15(1), 116-132. https://doi.org/10.1109/TSMC.1985.6313399

Thaler, R., \& De Bondt, W. F. M. (1985). Does the Stock Market Overreact? Journal of Finance, 40(3), 793-805. https://doi.org/10.1111/j.1540-6261.1985.tb05004.x

Vidyamurthy, G. (2004). Pairs Trading, "Quantitative Methods and Analysis." Wiley Finance.

Zadeh, L. A. (1965). Fuzzy sets. Information and Control, 8(3), 338-353. https://doi.org/10.1016/S0019-9958(65)90241-X

Zadeh, Lotfi A. (1973). Outline of a New Approach to the Analysis of Complex Systems and Decision Processes. Systems, Man and Cybernetics, IEEE Transactions On, SMC-3(1), 28-44. https://doi.org/10.1109/TSMC.1973.5408575

The article has been reviewed. Received in March 2016; accepted in October 2019. 